\title{
Case Report: Methanol Poisoning as a Trigger for the Presentation of Diabetes Mellitus: A Case Report
}

\author{
Seyed Reza Mousavi ${ }^{1}$, Bita Dadpour ${ }^{1}$, Mohammad Moshiri' ${ }^{1}$, Toktam Moghiman ${ }^{1}$,Hamid Khosrojerdi ${ }^{1}$, Fares Najari2 ${ }^{\text {* }}$ Q
}

1. Medical Toxicology Research Center, School of Medicine, Mashhad University of Medical Sciences, Mashhad, Iran.

2. Department of Forensic Medicine, School of Medicine, Shahid Beheshti University of Medical Sciences, Tehran, Iran.

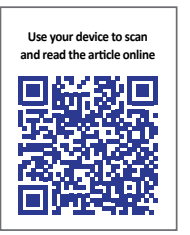

Citation: Mousavi SR, Dadpour B, Moshiri M, Moghiman T, Khosrojerdi H, Najari F. Methanol Poisoning as a Trigger for the Presentation of Diabetes Mellitus; A Case Report. International Journal of Medical Toxicology and Forensic Medicine. 2019; 9(3):151-154. https://doi.org/10.32598/ijmtfm.v9i3.25085

: https://doi.org/10.32598/ijmtfm.v9i3.25085

\section{(C) 0 (3)}

Article info:

Received: 21 Jan 2019

First Revision: 13 Feb 2019

Accepted: 25 May 2019

Published: 01 Jul 2019

\section{Keywords:}

Toxic alcohol, Methanol; Poisoning, Diabetic Ketoacidosis

\section{A B STRACT}

Background: The clinical and laboratory manifestations of methanol poisoning and Diabetic Ketoacidosis (DKA) might be very similar.

Case Presentation: A 15-year-old male, who lived in Mashhad, Iran, was referred to a medical toxicology center because of the loss of consciousness following the consumption of homemade alcohol. Laboratory tests revealed metabolic acidosis, the high blood levels of methanol, and ketonuria and glucosuria in urine analysis. The treatment of DKA and methanol poisoning was started simultaneously.

Conclusion: Methanol poisoning, as physical stress or because of pancreatitis as a complication, could be a trigger for diabetes in susceptible individuals, and physicians should be aware of the similarity of presentation of these situations.

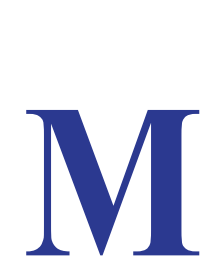

\section{Introduction}

ethanol poisoning often occurs because of the consumption of homemade alcohol by young people (Teenagers). On the other hand, the most common endocrine disease in young people is diabetes, and DKA is a common cause of hospital admissions in this age group. Various sources are mentioned as predisposing factors in the development of DKA, one of which is drug overdose and exposure to toxins. In this study, we evaluated the clinical and laboratory manifestations of a patient with DKA following methanol poisoning.

\section{Case Report}

A 15-year-old male patient was admitted in MTC with nausea and vomiting and abdominal pain 1 day after the consumption of home-made alcohol in a party. He complained of blurred vision on the afternoon of the same day. In his family history, father suffered from insulindependent diabetes and mother suffered from iron deficiency anemia using ferrous sulfate. Before referring

\footnotetext{
* Corresponding Author:

Fares Najari, MD.

Address: Department of Forensic Medicine, School of Medicine, Shahid Beheshti University of Medical Sciences, Tehran, Iran Tel: +98 (912) 3195140

E-mail:najar.hospital@sbmu.ac.ir
} 
to the hospital, the patient had an attack of generalized tonic-clonic seizures. On admission, the patient had localized painful stimulations, verbal response as groans and non-reactive to light, and mydriatic pupils. He had also acetone odor of the breath. Physical examination revealed systolic/diastolic blood pressure:90/60 $\mathrm{mmHg}$, axillary temperature: $37^{\circ} \mathrm{C}$, respiratory rate: $30 / \mathrm{min}$, and pulse rate:130/min. Electrocardiography showed sinus tachycardia and gasometry findings; PO2:90 mmHg, O2 Sat:90\%, pH:7.1, PCO2:15 mmHg, and bicarbonate: $10 \mathrm{mEq} / \mathrm{L}$. Urine analysis findings showed blood:+++, ketone:+++, and glucose:+++. Table 1 shows other laboratory tests.

In addition to the routine treatment of DKA, the required attempts for methanol poisoning were made, including folic acid [1], bicarbonate sodium, and ethanol based on toxic serum level of methanol; he underwent 4 hours hemodialysis as well. The following findings were reported after hemodialysis: Serum Methanol:35mg/ dL, Serum Ethanol:100mg/dL, Gasometry: PO2:90 mmHg, O2 Sat:90\%, pH:6.9, PCO2:20mmHg, and bicarbonate: $8 \mathrm{mEq} / \mathrm{L}$.

The patient underwent hemodialysis twice because of the high serum level of methanol and remained metabolic acidosis; unfortunately, he died because of ventricular tachyarrhythmia during the second hemodialysis. The deceased person was autopsied on the next day and toxicology tests reported no detectable level of ethanol and methanol, while the serum level of isopropyl alcohol was $10 \mathrm{mg} / \mathrm{dL}$.

\section{Discussion}

Methanol poisoning is relatively common in Iran [2] because of the consumption of home-made alcohol and a high mortality rate is anticipated if the beginning of treatment is delayed; the mortality rate of DKA with treatment is (1-3\%) [3]. A patient with diabetes with the previous recurrent attacks of DKA was reported, who experienced a refractory DKA because of methanol poisoning [4]; but, there is no report of the first presentation of diabetes because of methanol poisoning. Methanol poisoning may lead to metabolic acidosis and methanol metabolites (formaldehyde and formic acid) may cause severe damage to the optic nerve and central nervous system.

High osmolar gap is expected in this poisoning; on the other hand, the increased metabolism of fatty acids and ketoacids (acetoacetate and beta-hydroxybutyrate) accumulation lead to diabetic ketoacidosis [5]. This situation is more common in type 1 diabetes because of the discontinuation of insulin or physical stress such as pancreatitis [6], gastroenteritis [7], and myocardial infarction [8], which a transient increased need to insulin occurs in these conditions. Clinical manifestations (for example, nausea and vomiting, abdominal pain, impaired visual acuity, dyspnea, tachycardia, and tachypnea) in these situations are very similar; there are also several similarities in paraclinical manifestations such as hyperglycemia, metabolic acidosis, and hyperamylasemia [9].

The history of home-made alcohol use, the high serum concentration of methanol, in addition to metabolic

Table 1. Biochemical tests of the patient with DKA and methanol poisoning

\begin{tabular}{|c|c|}
\hline Variable Name & Amount \\
\hline $\mathrm{Na}$ & 130 (meq/L) \\
\hline $\mathrm{K}$ & $5.2(\mathrm{meq} / \mathrm{L})$ \\
\hline $\mathrm{Ca}$ & 9 (meq/L) \\
\hline $\mathrm{pH}$ & $2.5(\mathrm{mg} / \mathrm{dL})$ \\
\hline Serum methanol concentration & 70 (mg/dL) \\
\hline Serum Iron & $150(\mathrm{mcg} / \mathrm{dL})$ \\
\hline Serum amylase & $450(\mathrm{U} / \mathrm{L})$ \\
\hline Blood sugar & 350 (mg/dL) \\
\hline BUN & 40 (mg/dL) \\
\hline $\mathrm{Cr}$ & $1.8(\mathrm{mg} / \mathrm{dL})$ \\
\hline CPK & 15000 (U/L) \\
\hline
\end{tabular}


Table 2. Comparison of clinical signs and laboratory of methanol poisoning and DKA

\begin{tabular}{|c|c|c|}
\hline Variable Name & Methanol Poisoning & DKA \\
\hline Abdominal pain, nausea, vomiting & + & + \\
\hline Visual impairment & + & + \\
\hline Hyperglycemia & + & + \\
\hline Ketonuria & + & + \\
\hline Glycosuria & - & + \\
\hline Elevated serum amylase & $\stackrel{+}{+}$ & $\stackrel{+}{\stackrel{+}{\text { (Salivary gland origin) }}}$ \\
\hline Metabolic acidosis (high anion gap) & + & + \\
\hline
\end{tabular}

acidosis, seizure, and mydriasis [10] strongly suggested methanol poisoning, while the presence of hyperglycemia, metabolic acidosis, glucosuria, and ketonuria was consistent with DKA. Hypotension and tachycardia were explained in the context of dehydration in DKA and metabolic acidosis in both situations.

Relatively high potassium levels could be as a result of progressive metabolic acidosis as well as an acute renal failure, while the amount of total body potassium might decrease. The rise of Blood Urea Nitrogen (BUN) and $\mathrm{Cr}$ of serum was consistent with dehydration in DKA and also could be considered a complication of methanol poisoning. The seizure could explain high Creatine Phosphokinase (CPK) levels; although these amounts could not explain the occurrence of renal failure because of rhabdomyolysis.

Hyponatremia may be linked to increased blood sugar [11], as measured sodium of serum reduces in hyperglycemia. While the normal sodium of serum could be a sign of severe dehydration. The simultaneous treatment of these serious conditions can lead to unexpected problems. Although bicarbonate therapy is a verified treatment of metabolic acidosis in methanol poisoning [12], it is not recommended routinely in DKA because cardiac dysfunction, decreased tissue oxygenation [13], worsening of hypokalemia, and increased risk of cerebral edema, especially in children, are anticipated theoretically and practically. While the high serum concentration of methanol $(70 \mathrm{mg} / \mathrm{dL})$, the presence of metabolic acidosis, coma, and convulsion indicated hemodialysis in this case, in the context of DKA, it could result in the worsening of dehydration as a risk factor for the deterioration of acidosis [14]. Ethanol-induced Ketoacidosis [15] was another differential diagnosis although it can be rejected because of the presence of hyperglycemia.
It is noticeable that a detectable amount of isopropyl alcohol in blood sample taken from the femoral vein is the result of reverse production of this compound of blood ketone; this interaction would continue for several hours after death [16]; likewise, it is worth mentioning that isopropyl alcohol intoxication does not lead to metabolic acidosis [17] and this compound is eliminated well by hemodialysis [18].

\section{Summery}

Physicians must be aware of the similar symptoms and signs of these conditions; DKA and methanol poisoning and, in suspicious cases, appropriate diagnostic tests must be performed. Given some interactions between the treatment methods of these common conditions, precise follow-up is recommended. These conditions are compared in Table 2.

\section{Ethical Considerations}

\section{Compliance with ethical guidelines}

The study protocol was in conformity with the ethical guidelines of the 1975 Declaration of Helsinki, revised in 1983. Private information, including name, surname, and burial permit was removed from the data sheet to comply with ethical concerns.

\section{Funding}

This research did not receive any specific grant from funding agencies in the public, commercial, or not-forprofit sectors.

\section{Author's contributions}

All authors contributed in designing, running, and writing all parts of the research. 


\section{Conflict of interest}

The authors declared no conflict of interest.

\section{Acknowledgements}

The authors wish to thank the staff of the Poisoning Center of Emam Reza Hospital in Mashhad for their cooperation with the project and providing the files.

\section{References}

[1] Lim CS, Bryant SM. Forgoing the folate? Contemporary recommendations for methanol poisoning and evidence review. American Journal of Therapeutics. 2016; 23(3):e850-4. [DOI:10.1097/MJT.0000000000000059]

[2] Abrishami M, Khalifeh M, Shoayb M, Abrishami M. Therapeutic effects of high-dose intravenous prednisolone in methanol-induced toxic optic neuropathy. Journal of Ocular Pharmacology and Therapeutics. 2011; 27(3):261-3. [DOI:10.1089/ jop.2010.0145] [PMID]

[3] White PC, Dickson BA. Low morbidity and mortality in children with diabetic ketoacidosis treated with isotonic fluids The Journal of Pediatrics. 2013; 163(3):761-6. [DOI:10.1016/j. jpeds.2013.02.005] [PMID]

[4] Celik U, Celik T, Avci A, Annagur A, Yilmaz HL, Kucukosmanoglu $\mathrm{O}$, et al. Metabolic acidosis in a patient with type 1 diabetes mellitus complicated by methanol and amitriptyline intoxication. European Journal of Emergency Medicine. 2009; 16(1):45-8. [DOI:10.1097/MEJ.0b013e3283034245] [PMID]

[5] Hanas R, Ludvigsson J. Hypoglycemia and ketoacidosis with insulin pump therapy in children and adolescents. Pediatric Diabetes. 2006; 7(4):32-8. [DOI:10.1111/j.1399543X.2006.00169.x] [PMID]

[6] Pant N, Kadaria D, Murillo LC, Yataco JC, Headley AS, Freire AX. Abdominal pathology in patients with diabetes ketoacidosis. The American Journal of the Medical Sciences. 2012; 344(5):341-4. [DOI:10.1097/MAJ.0b013e3182449d4e] [PMID]

[7] Koh JS, Hahm JR, Jung JH, Jung TS, Rhyu SS, Moon SW, et al. Intussusception in a young female with Vibrio gastroenteritis and diabetic ketoacidosis. Internal Medicine. 2007 46(4):171-4. [DOI:10.2169/internalmedicine.46.1719] [PMID]

[8] Oo YH, Karam JG, Resta CA. Extreme insulin resistance in a patient with diabetes ketoacidosis and acute myocardial infarction. Case Reports in Endocrinology. 2013; 2013(520904):17. [DOI:10.1155/2013/520904] [PMID] [PMCID]

[9] Haddad NG, Croffie JM, Eugster EA. Pancreatic enzyme elevations in children with diabetic ketoacidosis. The Journal of Pediatric. 2004; 145(1):122-4. [DOI:10.1016/j. jpeds.2004.03.050] [PMID]

[10] Condò M, Marcello I, Zoppi F, Binetti R. [A cluster of methanol-related poisonings in Sicily: Case characterization and identification of unexpected sources of exposure (Italian)] Epidemiologia e Prevenzione. 2009; 33(3):104-12. [PMID]
[11] Sahin OZ, Asci G, Kircelli F, Yilmaz M, Duman S, Ozkahya $\mathrm{M}$, et al. The impact of low serum sodium level on mortality depends on glycemic control. European Journal of Clinical Investigation. 2012; 42(5):534-40. [DOI:10.1111/j.13652362.2011.02613.x] [PMID]

[12] Barceloux DG, Bond GR, Krenzelok EP, Cooper H, Vale JA. American academy of clinical toxicology ad hoc committee on the treatment guidelines for methanol poisoning. Journal of Toxicology: Clinical Toxicology. 2002; 40(4):415-46. [DOI:10.1081/CLT-120006745]

[13] Duhon B, Attridge RL, Franco-Martinez AC, Maxwell PR Hughes DW. Intravenous sodium bicarbonate therapy in severely acidotic diabetic ketoacidosis. Annals of Pharmacotherapy. 2013; 47(7-8):970-5. [DOI:10.1345/aph.1S014] [PMID]

[14] Mul D, Meijer CR. [Hyperglycaemic crises in children and adolescents (Dutch)]. The Nederlands Tijdschrift voor Geneeskunde. 2013; 157(50):A5185. [PMID]

[15] Elliott S, Smith C, Cassidy D. The post-mortem relationship between Beta-Hydroxybutyrate (BHB), acetone and ethanol in ketoacidosis. Forensic Science Internationa. 2010; 198(13):53-7. [DOI:10.1016/j.forsciint.2009.10.019] [PMID]

[16] Lewis GD, Laufman AK, McAnalley BH, Garriott JC. Metabolism of acetone to Isopropyl alcohol in rats and humans. Forensic Science Internationa. 1984; 29(2):541-9. [DOI:10.1520/ JFS11702J]

[17] Trullas JC, Aguilo S, Castro P, Nogue S. Life-threatening isopropyl alcohol intoxication: is hemodialysis really necessary? Veterinary and Human Toxicology. 2004; 46(5):282-4. [PMID]

[18] Jammalamadaka D, Raissi S. Ethylene glycol, methanol and Isopropyl alcohol intoxication. The American Journal of the Medical Sciences. 2010; 339(3):276-81. [DOI:10.1097/ MAJ.0b013e3181c94601] [PMID] 